\title{
Organogênese direta de Orthophytum mucugense
}

\author{
Direct organogenesis of Orthophytum mucugense
}

\section{Carolina Oliveira de Cerqueira LimaI Maria Nazaré Guimarães MarchiII Alone Lima-BritoII Claudia Elena Carneiro ${ }^{\mathrm{III}}$ Moema Cortizo Bellintani ${ }^{\mathrm{IV}}$ José Raniere Ferreira de Santana ${ }^{\mathrm{III}}$}

\section{RESUMO}

Orthophytum mucugense é uma bromélia ornamental endêmica do município de Mucugê-BA que está passível de extinção. O objetivo deste trabalho foi estabelecer um protocolo de regeneração via organogênese direta para a espécie. Os explantes raiz, caule e folha, oriundos de plantas com diferentes idades, foram inoculados em meio de cultura MS $1 \frac{1}{2}$ suplementado com BAP e ANA. Os brotos foram inoculados em meio contendo AIB e carvão ativo. As plantas foram transferidas para substrato composto de vermiculita $e$ terra. A maior taxa de brotação foi obtida com o explante caule com 20 e 40 dias de idade em meio com 0,65mM de ANA. Na fase de enraizamento, a presença de carvão ativo interferiu positivamente no comprimento da parte aérea e do sistema radicular das plantas. As plantas foram aclimatizadas com $100 \%$ de sobrevivência.

Palavras-chave: Bromeliaceae, cultura de tecidos, micropropagação, plantas ornamentais.

\section{ABSTRACT}

Orthophytum mucugense is an ornamental bromeliad endemic to the municipality of Mucugê-BA which is vulnerable to extinction. The aim of this study was to establish a regeneration protocol via direct organogenesis for the species. The explants root, stem and leaf from plants of different ages were inoculated in the MS $1 / 2$ culture medium supplemented with BAP and NAA. The shoots were inoculated on medium supplemented with IBA and activated charcoal. The plants were transferred to a substrate composed of vermiculite and soil. The highest rate of sprouting was obtained with stem explants of 20 and 40 days old in medium supplemented with
$0.65 \mathrm{mM}$ of NAA. For rooting the presence of activated charcoal had a positive influence on the length of shoot and root plants system. The plants were acclimatized with $100 \%$ survival.

Key words: Bromeliaceae, tissue culture, micropropagation, ornamental plants.

\section{INTRODUÇÃO}

Orthophytum mucugense WAND e CONCEIÇÃO é uma bromélia restrita à Chapada Diamantina-BA. As suas folhas são verdes e, na época de floração, tornam-se parcial ou completamente vermelhas, conferindo notável valor ornamental à espécie (WANDERLEY \& CONCEIÇÃO, 2006). O endemismo associado ao extrativismo a torna vulnerável e desperta a necessidade de estudos relacionados à sua propagação.

Métodos de cultura de tecidos têm sido aplicados na conservação e multiplicação de genótipos específicos de bromélias. Uma das vias mais utilizadas para a regeneração dos brotos in vitro é a organogênese direta que é benéfica em termos da estabilidade genética e vem sendo utilizada em diversas espécies da família Bromeliaceae para a produção comercial de mudas, regeneração de plantas geneticamente modificadas e multiplicação de plantas conservadas in vitro.

IPrograma de Pós-graduação em Biotecnologia, Universidade Estadual de Feira de Santana (UEFS), 44036-336, Feira de Santana, BA, Brasil. E-mail: cerqueira.carolina@gmail.com. Autor para correspondência.

IPrograma de Pós-graduação em Recursos Genéticos Vegetais, UEFS, Feira de Santana, BA, Brasil.

IIIDepartamento de Biologia, UEFS, Feira de Santana, BA, Brasil.




A regeneração de plantas in vitro é um processo complexo que envolve diversos fatores, como o genótipo, a fonte e as condições fisiológicas do explante, a combinação de reguladores vegetais exógenos, o meio de cultura utilizado e as condições ambientais (LUCIANI et al., 2006).

O objetivo deste trabalho foi estabelecer um protocolo de regeneração via organogênese direta para Orthophytum mucugense.

\section{MATERIAL E MÉTODOS}

Condições de cultivo - As culturas foram mantidas em sala de crescimento sob temperatura de $25 \pm 2{ }^{\circ} \mathrm{C}$, fotoperíodo de $16 \mathrm{~h}$ e densidade de fluxo de fótons fotossinteticamente ativos de $60 \mu \mathrm{mol} \mu \mathrm{m}^{-2} \mathrm{~s}^{-1}$.

Micropropagação - Plantas germinadas in vitro com 20, 40 e 60 dias de idade foram seccionadas transversalmente em raiz, caule e folha. Essas plantas foram colocadas no escuro 15 dias antes da utilização, para indução do estiolamento. Os explantes foram inoculados em tubo de ensaio $(25 \times 150 \mathrm{~mm})$ com $15 \mathrm{~mL}$ de meio MS (MURASHIGE \& SKOOG, 1962) com metade da concentração salina (MS1/2) suplementado com $2,22 \mu \mathrm{M}$ de BAP(BELLINTANI et al., 2008) e duas concentrações de ANA, 0,65 e 1,30 $\mu \mathrm{M}$. O delineamento amostral foi inteiramente casualizado em arranjo fatorial $3 \times 3 \times 2$ (idade do explante $\mathrm{x}$ tipo de explante $\mathrm{x}$ concentração de ANA), com 12 repetições de cinco amostras. Aos 60 dias, as variáveis analisadas foram número de brotos por explante, porcentagem de explantes com brotos e comprimento dos brotos.

Análise histológica - Para identificar a via de regeneração dos brotos, durante a micropropagação, cinco amostras de tecido foliar e caulinar de cada tratamento foram periodicamente retiradas e fixadas em álcool $70 \%$. As amostras foram cortadas longitudinalmente e transversalmente à mão livre, com auxílio de lâmina de barbear. Os cortes foram clarificados com hipoclorito de sódio a 3\% por 15 minutos, lavados em água destilada, corados com safrablau, analisados em microscópio óptico e fotografados (BUKATSCH, 1972).

Enraizamento - Brotos micropropagados com aproximadamente $5 \mathrm{~mm}$ de comprimento foram inoculados em meio $\mathrm{MS}^{1} 1 / 2$ suplementado com $\operatorname{AIB}(0,00$; $1,11$ e $2,22 \mu \mathrm{M})$ e carvão ativo $\left(0 \mathrm{e} 1 \mathrm{~g} \mathrm{~L}^{-1}\right)$. O delineamento experimental foi inteiramente casualizado em arranjo fatorial $3 \times 2$ (concentração de AIB x concentração de carvão ativo), com 12 repetições de cinco amostras. Aos 60 dias, as variáveis analisadas foram comprimento e peso seco da parte aérea e sistema radicular. Brotos enraizados foram transferidos para substrato composto de vermiculita e terra na proporção volumétrica de $1: 1$ e mantidos em viveiro com $70 \%$ de luminosidade durante 30 dias.

Análise estatística - Os dados foram submetidos à análise de variância (ANOVA) e as médias comparadas pelo teste Tukey $(0,05)$, utilizando o programa estatístico SISVAR (v. 4.4, UFLA).

\section{RESULTADOS E DISCUSSÃO}

O caule foi o primeiro explante a emitir resposta morfogenética in vitro, após uma semana de inoculação, seguido do explante folha, cuja resposta iniciou-se duas semanas depois. O caule apresentou as maiores médias para as variáveis porcentagem de explantes com brotos $(46,11$ e 43,33) e número de brotos por explante $(1,21$ e 0,87$)$ independente da concentração de regulador aplicada, diferindo significativamente dos explantes folha e raiz (Tabela 1). Esses resultados corroboram os obtidos para Syngonanthus mucugensis por LIMA-BRITO et al. (2011) e pode ser atribuído à maior presença de tecidos meristemáticos no caule, quando comparados às folhas e raízes. Apesar de as folhas possuírem o meristema axilar, localizado na junção entre a sua base e o caule (LONG \& BARTON, 2000), a retirada da planta mãe pode ter ocasionado

Tabela 1 - Percentual de explantes com brotos, número de brotos por explante e comprimento dos brotos de Orthophytum mucugense obtidos a partir dos explantes caule, folha e raiz em meio suplementado com $2,22 \mu \mathrm{M}$ de BAP, associado a duas concentrações de ANA após 60 dias de cultivo.

\begin{tabular}{|c|c|c|c|}
\hline \multirow{2}{*}{ ANA $(\mu \mathrm{M})$} & \multicolumn{3}{|c|}{ 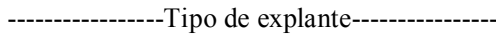 } \\
\hline & Caule & Folha & Raiz \\
\hline & \multicolumn{3}{|c|}{-----\% de explantes com brotos-- } \\
\hline 0,65 & $46,11 \mathrm{~A}^{\mathrm{w}} \mathrm{a}^{\mathrm{z}}$ & $9,44 \mathrm{Ab}$ & $0,00 \mathrm{Ab}$ \\
\hline \multirow[t]{2}{*}{1,30} & $43,33 \mathrm{Aa}$ & $14,44 \mathrm{Ab}$ & $0,00 \mathrm{Ac}$ \\
\hline & \multicolumn{3}{|c|}{----------Número de brotos/explante--------- } \\
\hline 0,65 & $1,21 \mathrm{Aa}$ & $0,26 \mathrm{Ab}$ & $0,00 \mathrm{Ab}$ \\
\hline \multirow[t]{2}{*}{1,30} & $0,87 \mathrm{Ba}$ & $0,33 \mathrm{Ab}$ & $0,00 \mathrm{Ab}$ \\
\hline & \multicolumn{3}{|c|}{------Comprimento dos brotos $(\mathrm{mm})$------ } \\
\hline 0,65 & $5,53 \mathrm{Aa}$ & $1,63 \mathrm{Ab}$ & $0,00 \mathrm{Ac}$ \\
\hline 1,30 & $4,18 \mathrm{Ba}$ & $2,71 \mathrm{Aa}$ & $0,00 \mathrm{Ab}$ \\
\hline
\end{tabular}

${ }^{\text {w }}$ Médias seguidas pela mesma letra maiúscula na mesma coluna, para cada variável, não diferem entre si ao nível de $5 \%$ de probabilidade pelo teste de Tukey.

${ }^{\mathrm{z}}$ Médias seguidas pela mesma letra minúscula na mesma linha, não diferem entre si ao nível de $5 \%$ de probabilidade pelo teste de Tukey. 
perda de parte deste tecido, o que justificaria a sua baixa taxa de regeneração em relação ao explante caule.

O explante raiz não apresentou competência morfogenética nas condições as quais foi submetido, o que pode ser atribuída à extrema diferenciação deste órgão em algumas espécies, como em Syngonanthus mucugensis (LIMA-BRITO et al., 2011). Entretanto, na espécie Solanum paludosum o explante raiz demonstrou competência para a formação de brotos (BELTRÃO et al. 2008). Uma possível causa para a manutenção do potencial organogenético das raízes está na retenção da atividade meristemática em algumas células do periciclo (MAUGHAN et al. 2006).

Quanto à concentração de ANA, observase que, para o explante caule, o aumento da concentração desse regulador reduziu significativamente o número de brotos/explante e o comprimento médio de brotos (Tabela 1). Para Vriesea gigantea, Nidularium fulgens e Vriesea reitzzi o aumento da concentração de ANA reduziu a habilidade de regeneração de brotos in vitro (BENCKE \& DROSTE, 2008, PAIVAetal. 2009, DALVESCO \& GUERRA, 2010), o que corrobora os resultados encontrados neste trabalho.

Segundo SILVA et al. (2007), muitos protocolos de multiplicação para espécies de bromélias consideram o uso do BAP associado a baixas concentrações de ANA. No entanto, os resultados obtidos neste trabalho discordam dos encontrados para Billbergia rosae e Neoglaziovia variegata, em que maiores concentrações de ANA aumentaram significativamente a quantidade de brotos (PARDO et al., 2008; SILVEIRA et al., 2009). Para o abacaxizeiro ornamental Ananas comosus var. erectifolius, o aumento na concentração de ANA favoreceu o crescimento da parte aérea de brotos micropropagados (PASQUAL et al., 2008), o que também contraria os resultados encontrados para $\boldsymbol{O}$. mucugense.

O explante caule com 20 e 40 dias de idade apresentou uma maior porcentagem de formação de brotos, 48,33 e 56,67, respectivamente (Tabela 2). Essas taxas foram semelhantes às observadas em Vriesea gigantea, mas inferiores à encontrada em $\boldsymbol{V}$. philippocoburgi, (DROSTE et al., 2005). O número médio de brotos obtidos para Neoreglia cruenta também foi inversamente proporcional à idade do explante, pois explantes mais jovens (49 dias) apresentaram um percentual de brotação superior a explantes mais velhos (154 dias), 64,28\% e 22 a 33\%, respectivamente (CARNEIRO et al. 1999). Entretanto, para a bromélia Tillandsia eizii, a idade do explante, 21 e 84 dias, não afetou significativamente as variáveis \% de explantes com brotos e número de brotos/explante
Tabela 2 - Percentual de explantes com brotos, número de brotos por explante e comprimento dos brotos em Orthophytum mucugense obtidos a partir do explante caule com 20, 40 e 60 dias de idades em meio suplementado com $2,22 \mu \mathrm{M}$ de BAP, associado a duas concentrações de ANA, após 60 dias de cultivo.

\begin{tabular}{|c|c|c|c|}
\hline \multirow{2}{*}{ ANA $(\mu \mathrm{M})$} & \multicolumn{3}{|c|}{----------Idade do explante (dias) --------- } \\
\hline & 20 & 40 & 60 \\
\hline & \multicolumn{3}{|c|}{---------\% de explantes com brotos--------- } \\
\hline 0,65 & $55,00 \mathrm{~A}^{\mathrm{w}} \mathrm{a}^{\mathrm{z}}$ & $50,00 \mathrm{Aab}$ & $33,33 \mathrm{Ab}$ \\
\hline \multirow[t]{2}{*}{1,30} & $48,33 \mathrm{Aa}$ & $56,67 \mathrm{Aa}$ & $25,00 \mathrm{Ab}$ \\
\hline & \multicolumn{3}{|c|}{--------Número de brotos/explante--------- } \\
\hline 0,65 & $1,02 \mathrm{Aa}$ & $1,25 \mathrm{Aa}$ & $1,37 \mathrm{Aa}$ \\
\hline \multirow[t]{2}{*}{1,30} & $0,95 \mathrm{Aab}$ & $1,30 \mathrm{Aa}$ & $0,37 \mathrm{Bb}$ \\
\hline & \multicolumn{3}{|c|}{------ Comprimento dos brotos $(\mathrm{mm})$------ } \\
\hline 0,65 & $4,62 \mathrm{Ab}$ & $7,80 \mathrm{Aa}$ & $4,15 \mathrm{Ab}$ \\
\hline 1,30 & $4,15 \mathrm{Aab}$ & $5,99 \mathrm{Aa}$ & $2,40 \mathrm{Ab}$ \\
\hline
\end{tabular}

${ }^{\mathrm{w}}$ Médias seguidas pela mesma letra maiúscula na mesma coluna, para cada variável, não diferem entre si ao nível de $5 \%$ de probabilidade pelo teste de Tukey.

${ }^{2}$ Médias seguidas pela mesma letra minúscula na mesma linha não diferem entre si ao nível de $5 \%$ de probabilidade pelo teste de Tukey.

(PICKENS et al. 2006). O sucesso na propagação de explantes mais jovens pode ser atribuído à existência de muitas células meristemáticas e indiferenciadas que apresentam crescimento rápido, o que é essencial para iniciar as culturas (SHIN et al., 2000; BISPO et al., 2007). Quanto à variável comprimento médio de brotos, explantes com 40 dias de idade, independente da concentração de regulador aplicada, produziram brotos maiores, 7,80 e 5,99mm, não diferindo significativamente apenas do caule com 20 dias na concentração de $1,30 \mu \mathrm{M}$ de ANA. O aumento da concentração de ANA reduziu o número de brotos/explante em segmentos caulinares com 60 dias de idade (Tabela 2).

A partir da análise histológica, foi possível constatar que a exposição dos explantes em meio com regulador de crescimento proporcionou regiões de intensa divisão celular (Figura 1). No explante caule, a origem da região com atividade mitótica ocorreu no câmbio vascular com a formação de células com características meristemáticas, sendo essas pequenas, com núcleo proeminente e divisões celulares periclinais e anticlinais (Figura 1A-C). A formação dos brotos ocorreu por organogênese direta nas duas fontes de explante utilizadas, devido à formação de um tecido apenas com o eixo caulinar (monopolar) e a junção observada entre os feixes vasculares dos brotos com o explante (Figura 1C-E). A organogênese direta também foi evidenciada pela presença da ligação entre os vasos condutores do explante e dos brotos (Figura 1C-E), e a 


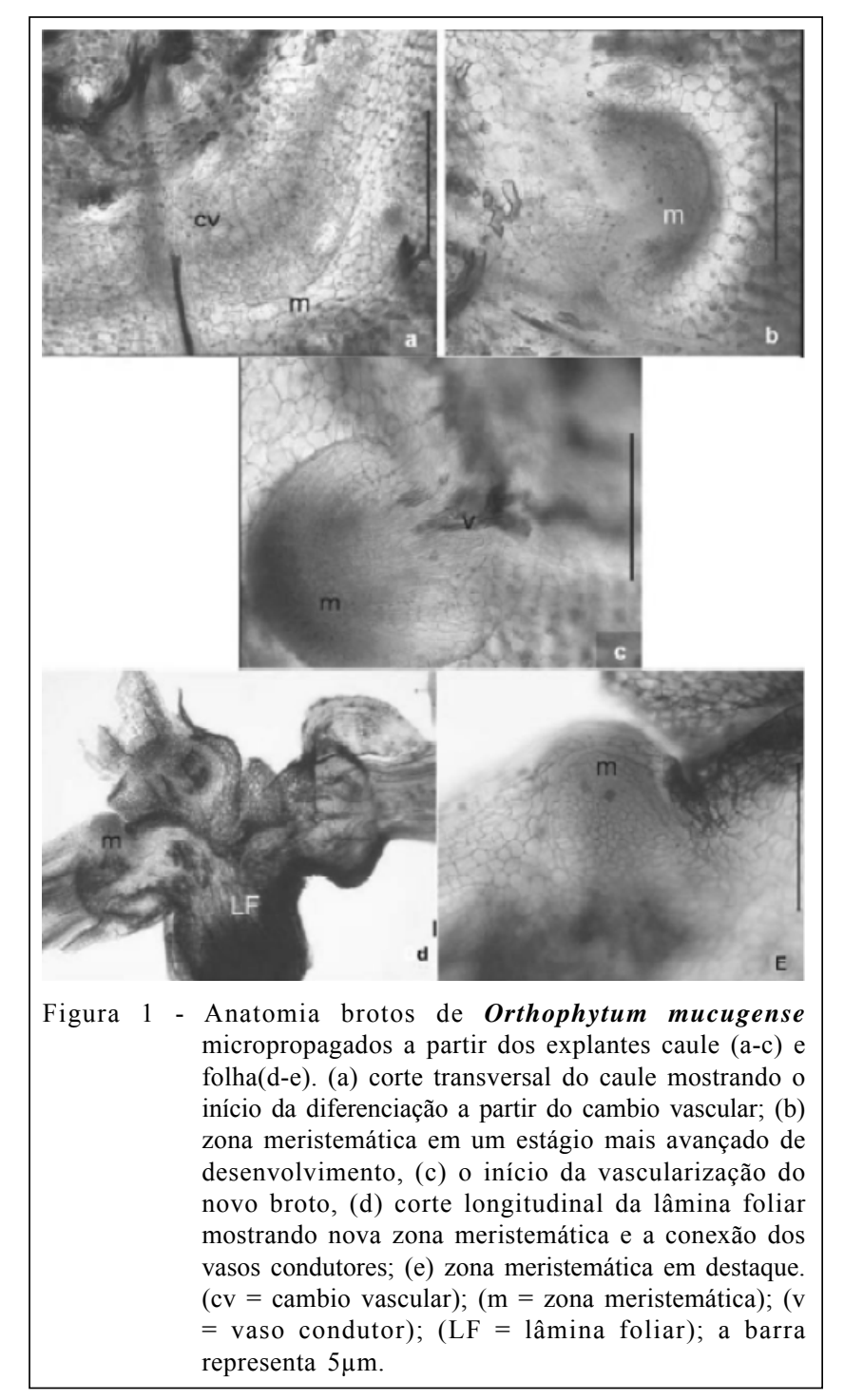

ausência da desdiferenciação do tecido com a passagem pela fase de calo antes da formação do broto. Nas folhas, a diferenciação ocorreu no parênquima clorofiliano onde foi possível observar células em divisões periclinais e anticlinais (Figura $1 \mathrm{e}$ ).

O AIB, nas concentrações testadas, não favoreceu a rizogênese in vitro de $\boldsymbol{O}$. mucugensis, e o aumento da sua concentração associado à presença de carvão ativo teve um efeito negativo sobre o comprimento das raízes, reduzindo-as significativamente de tamanho $(33,16 \mathrm{~mm})$ (Tabela 3$)$. Esses resultados estão de acordo com os encontrados para a bromélia Vriesea scalaris e para o híbrido PExSC52 do abacaxizeiro, demostrando que outros fatores como o tamanho da parte aérea e a produção endógena de auxina pela planta, interferem na rizogênese (BARBOZA et al., 2004; SILVA et al., 2009).
Assim, o fato do AIB nas condições testadas não ter favorecido o enraizamento de $\boldsymbol{O}$. mucugensis não garante que outras concentrações desta ou de outras auxinas não sejam benéficas. Afinal, para outras espécies de bromélias como Vriesea cacuminis, Ananas comosus e Aechmea blanchetiana, a presença de auxinas, como ANA e AIB, favoreceu o enraizamento (MENDES et al., 2007; CHU et al., 2010; MORAES et al., 2010).

Por outro lado, a presença de carvão ativo interferiu positivamente no comprimento da parte aérea e do sistema radicular de brotos. Na sua ausência e em meio suplementado com $1,11 \mu \mathrm{M}$ de regulador, o tamanho da parte aérea $(27,80 \mathrm{~mm})$ e do sistema radicular $(21,22$ e $22,76 \mathrm{~mm})$ foram significativamente menores que os observados nos demais tratamentos (Tabela 3 ). O carvão ativo favorece o enraizamento in vitro, dentre 
Tabela 3 - Média do comprimento da parte aérea e das raízes e matéria seca da parte aérea e das raízes de brotos de Orthophytum mucugense desenvolvidos em meio MS 1/2 suplementado com carvão ativado e AIB, após 60 dias de cultivo.

\begin{tabular}{|c|c|c|}
\hline \multirow[t]{2}{*}{$\operatorname{AIB}(\mu \mathrm{M})$} & \multicolumn{2}{|c|}{ 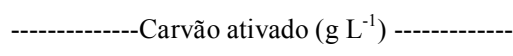 } \\
\hline & 0,0 & 1,0 \\
\hline & \multicolumn{2}{|c|}{------Comprimento da parte aérea $(\mathrm{mm})$----- } \\
\hline 0,00 & $35,76 \mathrm{~A}^{\mathrm{w}} \mathrm{a}^{\mathrm{z}}$ & $37,06 \mathrm{Aa}$ \\
\hline 1,11 & $27,80 \mathrm{Ab}$ & $39,78 \mathrm{Aa}$ \\
\hline \multirow[t]{2}{*}{2,22} & $32,18 \mathrm{Aa}$ & $40,72 \mathrm{Aa}$ \\
\hline & \multicolumn{2}{|c|}{------Comprimento das raízes $(\mathrm{mm})$------ } \\
\hline 0,00 & $22,76 \mathrm{Ab}$ & $49,06 \mathrm{Aa}$ \\
\hline 1,11 & $21,22 \mathrm{Ab}$ & $46,08 \mathrm{Aba}$ \\
\hline \multirow[t]{2}{*}{2,22} & $34,52 \mathrm{Aa}$ & $33,16 \mathrm{Ba}$ \\
\hline & \multicolumn{2}{|c|}{---Matéria seca da parte aérea (mg/planta)--- } \\
\hline 0,00 & $26,00 \mathrm{Aa}$ & $16,00 \mathrm{Aa}$ \\
\hline 1,11 & $16,00 \mathrm{Aa}$ & $20,00 \mathrm{Aa}$ \\
\hline \multirow[t]{2}{*}{2,22} & $22,00 \mathrm{Aa}$ & $18,00 \mathrm{Aa}$ \\
\hline & \multicolumn{2}{|c|}{----Matéria seca das raízes (mg/planta)----- } \\
\hline 0,00 & $3,40 \mathrm{Aa}$ & $2,40 \mathrm{Aa}$ \\
\hline 1,11 & $2,60 \mathrm{Aa}$ & $3,20 \mathrm{Aa}$ \\
\hline 2,22 & $5,40 \mathrm{Aa}$ & $2,20 \mathrm{Ab}$ \\
\hline
\end{tabular}

${ }^{\mathrm{w}}$ Médias seguidas pela mesma letra maiúscula, na mesma coluna, não diferem entre si em nível de $5 \%$ de probabilidade pelo teste de Tukey.

${ }^{\mathrm{z}}$ Médias seguidas pela mesma letra minúscula, na mesma linha, para cada variável, não diferem entre si em nível de $5 \%$ de probabilidade pelo teste de Tukey.

outros fatores, por simular condições de escuro que interfere na atividade e/ou na estabilidade de reguladores vegetais (PAN \& STADEN, 1998). Entretanto, para algumas espécies como Pyrus communis e Bauhinia cheilantha, a presença do carvão ativo não favoreceu a rizogênese (DAMIANI \& SHUCH, 2009; GUTIÉRREZ et al. 2011). As únicas variáveis que não sofreram influência do carvão ativo foram a massa seca da parte aérea e do sistema radicular, sendo que para esta última houve um decréscimo quando associado com 2,22 $\mathrm{MM}$ de AIB (Tabela 3).

As plantas aclimatizadas apresentaram 100\% de sobrevivência aos 30 dias da transferência.

\section{CONCLUSÃO}

A micropropagação do $\boldsymbol{O}$. mucugense via organogênese direta pode ser feita utilizando-se o explante caule entre 20 e 40 dias de idade em meio $\mathrm{MS}^{1} / 2$ suplementado com $0,65 \mathrm{mM}$ de ANA e 2,22 $\mathrm{mM}$ de BAP. A presença de carvão ativo $\left(1 \mathrm{~g} \mathrm{~L}^{-1}\right)$ interferiu positivamente no comprimento da parte aérea e do sistema radicular dos brotos.

\section{REFERÊNCIAS}

BELLINTANI, M.C. et al. Resposta regenerativa in vitro de explantes caulinares de bromélias endêmicas da Chapada Diamantina - Bahia. Magistra, v.20, n.4, p.328-337, 2008. Disponível em: $<$ http://www.magistra.ufrb.edu.br/3_07_20_4.html>. Acesso em: 03 out. 2011.

BELTRÃO, A.E.S. et al. Cultura in vitro de Solanum paludosum: regeneração. Revista Caatinga, v.21, n.4, p.79-82, 2008. Disponível em: $<$ http://200.137.6.4/revistas/index.php/sistema/ article/view/335/413>. Acesso em: 03 out. 2011.

BENCKE, M.; DROSTE, A. Otimização da micropropagação de Vriesea gigantea gaudich. (Bromeliaceae), uma espécie ameaçada de extinção, nativa do Rio Grande do Sul, Brasil. Pesquisas, Botânica. n.59, p.299-306, 2008. Disponível em: $<$ http://www.anchietano.unisinos.br/publicacoes/botanica/ botanica59/artigo16.pdf>. Acesso em: 03 out. 2011.

BARBOZA, S.B.S.C. et al. Micropropagação do abacaxizeiro híbrido PExSC-52 e da cv. Smooth Cayenne. Pesquisa Agropecuária Brasileira, v.39, n.8, p.725-733, 2004. Disponível em: $<$ http:/ /www.scielo.br/pdf/pab/v39n8/21732.pdf>. Acesso em: 03 out. 2011. doi: 10.1590/S0100-204X2004000800001.

BISPO, N.B. et al. Indução de embriogênese somática em diferentes explantes de aveia. (Avena sativa L.). Ciência Rural, v.37, n.3, p. 890-893, 2007. Disponível em: <http://www.scielo.br/ pdf/cr/v37n3/a47v37n3.pdf>. Acesso em: 03 out.2011. doi: 10.1590/S0103-84782007000300046.

BUKATSCH, F. Bermerkunger zur doppelfarbung astrablausafranin. Mikrokosmos, v.61, p.255, 1972.

CARNEIRO, L.A. et al. In vitro regeneration from leaf explants of Neoregelia cruenta (R. Graham) L.B. Smith, an endemic bromeliad from Eastern Brazil. Plant Cell, Tissue and Organ Culture, v.55, p.79-83, 1999. Disponível em: <http:// www.springerlink.com/content/j66107124h54p102/ fulltext.pdf $>$. Acesso em: 03 out. 2011. doi: 10.1023/ A: 1006186627580 .

CHU, E.P. et al. Effects of auxins on soluble carbohydrates, starch and protein content in Aechmea blanchetiana (Bromeliaceae) cultured in vitro. Scientia Horticulture. v.125, p.451-455, 2010. Disponível em: $<$ http://www.sciencedirect.com/ science/article/pii/S0304423810001755>. Acesso em: 03 out. 2011. doi: 10.1016/j.scienta.2010.04.021.

DAL VESCO, L.L.; GUERRA, M.P. In vitro morphogenesis and adventitious shoot mass regereration of Vriesea reitzii from nodular cultures. Scientia Horticulture. v.125, p.748-755, 2010. Disponível em: <http://www.sciencedirect.com/science/ article/pii/S0304423810002566>. Acesso em: 03 out.2011. doi: 10.1016/j.scienta.2010.05.030.

DAMIANI C.R.; SCHUCH M.W. Diferentes substratos a ambientes no enraizamento in vitro de mirtilo. Ciência Rural, v.39, n.2, p.563-566, 2009. Disponível em: <http:// www.scielo.br/pdf/cr/v39n2/a40v39n2.pdf >. Acesso em: 03 out. 2011. doi: 10.1590/S0103-84782009000200040.

DROSTE, A. et al. In vitro culture of Vriesea gigantea and Vriesia philippocoburgii: two vulnerable bromeliads native to southern Brazil. Brazilian Archives of biology and Technology, v.48, 
n.5, p.717-722, 2005. Disponível em: <http://www.scielo.br/pdf/ babt/v48n5/26606.pdf>. Acesso em: 03 out. 2011. doi: 10.1590/ S1516-89132005000600005.

GUTIÉRREZ, I.E.M. et al. Regeneração in vitro via organogênese direta de Bauhinia cheilantha. Ciência Rural, v.41, n.2, p.260-265, 2011. Disponível em: <http://submission.scielo.br/ index.php/cr/article/view/36174/3828>. Acesso em: 03 out. 2011. doi: 10.1590/S0103-84782011000200013.

LIMA-BRITO, A. et al. In vitro MORPHOGENESIS OF Syngonanthus mucugensis GIUL. SUBSP. mucugensis. Ciência e agrotecnologia, v.35, n.3, p.502-510, 2011. Disponível em: <http://www.scielo.br/pdf/cagro/v35n3/10.pdf > . Acesso em: 03 out. 2011. doi: 10.1590/S1413-70542011000300010.

LONG, J.; BARTON, M.K. Initiation of axillary and floral Meristems in Arabidopsis. Developmental Biology, v.218, p.341-353, 2000. Disponível em: <http://www.sciencedirect.com/ science/article/pii/S0012160699995726>. Acesso em 03 out. 2011. doi: 10.1006/dbio.1999.9572.

LUCIANI, G.F. et al. Effects of explants and growth regulators in garlic callus formation and plant regeneration. Plant Cell, Tissue and Organ Culture, v.87, p.39-143, 2006. Disponível em: <http://www.springerlink.com/content/f077085430388ph3/ fulltext.pdf $>$. Acesso em: 03 out. 2011. doi: 10.1007/s11240006-9148-5.

MAUGHAN, S.C. et al. A greenprint for growth: signalling the pattern of proliferation. Current Opinion in Plant Biology, v.9, p.490-495, 2006. Disponível em: <http:// www.sciencedirect.com/science/article/pii/S1369526606001166>. Acesso em: 03 out. 2011. doi: 10.1016/j.pbi.2006.07.010.

MENDES, G.C. et al. Enraizamento in vitro de Vriesea cacuminis L.B.Smith (BROMELIACEAE) do Parque Estadual de Ibitipoca, Minas Gerais, Brasil. Revista Brasileira de Biociências. v.5, sup1.2, p.969-971, 2007. Disponível em: <http:// www6.ufrgs.br/seerbio/ojs/index.php/rbb/article/view/794/676>. Acesso em: 03 out. 2011.

MORAES, A.M. et al. Micropropagação do abacaxizeiro cv. Emepa 1. Revista Brasileira de Engenharia Agricola e Ambiental, v.14, n.9, p.932-936, 2010. Disponível em: <http:/ /www.scielo.br/pdf/rbeaa/v14n9/a04v14n9.pdf>. Acesso em: 03 out. 2011. doi: 10.1590/S1415-43662010000900004.

MURASHIGE, T.; SKOOG, F. A revised medium for rapid growth and bioassays with tobacco tissue culture. Physiologia Plantarum, v.15, p.473-497, 1962. Disponível em: <http:// onlinelibrary.wiley.com/doi/10.1111/j.13993054.1962.tb08052.x/pdf $>$. Acesso em: 03 out. 2011. doi: 10.1111/j.1399-3054.1962.tb08052.x.

PAIVA, P.D.O. et al. In vitro propagation of Nidularium fulgens Lem. Interciência, v.34, n.8, p.593-596, 2009. Disponível em: <http://www.scielo.org.ve/pdf/inci/v34n8/art14.pdf >. Acesso em: 03 out. 2011.

PAN, M.J.; STADEN, J.V. The use of charcoal in in vitro culture - a review. Plant Growth Regulation. v.25, p.155163, 1998. Disponível em: <http://www.springerlink.com/ content/n3q6uhrwr745rp25/fulltext.pdf>. Acesso em: 03 out. 2011. doi: 10.1023/A:1006119015972.

PARDO, A. et al. Regeneración in vitro de Billbergia rosae Hortus ex Berr a partir de ápices caulinares. Boletín Del Centro de Investigaciones Biológicas, v.42, n.4, p.491505, 2008. Disponível em: <http://serbi.luz.edu.ve/ojs-2.3.4/ index.php/bcib/article/viewFile/31/31>. Acesso em: 03 out. 2011.

PASQUAL, M. et al. Micropropagação do abacaxizeiro ornamental. Horticultura Brasileira, v.26, p.045-049, 2008. Disponível em: $<$ http://www.scielo.br/pdf/hb/v26n1/a09v26n1.pdf $>$. Acesso em: 03 out. 2011.

PICKENS, K.A. et al. Adventitiuos bud development and regeration in Tillandsia eizii. In Vitro Cellular Developmental Biology - Plant, v.42, p.348-353, 2006. Disponível em: <http:/ /www.springerlink.com/content/934355442711h40v/ fulltext.pdf $>$. Acesso em: 03 out. 2011. doi: 10.1079/ IVP2006779.

SHIN, D. et al. A shoot regeneration protocol effective on diverse genotypes of sunflower (Helianthus annus L.). In vitro Cellular Develompental Bioloy-Plant, v.36, p.273278, 2000. Disponível em: <http://www.springerlink.com/ content/a122h06587676083/fulltext.pdf $>$. Acesso em: 03 out. 2011. doi: 10.1007/s11627-000-0050-2.

SILVA, A.L.L. et al. Micropropagation of Dyckia agudensis Irgang \& Sobral - an extinction threatened bromeliad. Iheringia, Série Botânica, v.62, n.1, p.39-43, 2007. Disponível em: <http://www.artigocientifico.com.br/uploads/ artc_1195408504_79.pdf>. Acesso em: 03 out. 2011.

SILVA, A.L.L. et al. In vitro multiplication of Vriesea scalaris E. Morren (Bromeliaceae). Iheringia, Série Botânica, v.64, n.2, p.151-156, 2009. Disponível em: <http://www.fzb.rs.gov.br/ publicacoes/iheringia-botanica/Ih64-2-p151-155.pdf >. Acesso em: 03 out. 2011.

SILVEIRA, D.G. et al. Micropropagation and in vitro Conservation of Neoglaziovia variegata (Arr. Cam.) Mez, a Fiber Producing Bromeliad from Brazil. Brazilian Archives of Biology and Technology, v.52, n.4, p.923-932, 2009. Disponível em: <http:/ /www.scielo.br/pdf/babt/v52n4/v52n4a16.pdf >. Acesso em: 03 out. 2011. doi: 10.1590/S1516-89132009000400015.

WANDERLEY, M.G.L.; CONCEIÇÃO, A.A. Notas taxonômicas e uma nova espécie do gênero Orthophytum Beer (Bromeliaceae) da Chapada Diamantina, Bahia, Brasil. Sitientibus (Série Ciências Biológicas), v.6, n.1, p.3-8, 2006. 